Supporting information for

\title{
Metallic Tungsten Nanoparticles That Exhibit an Electronic State Like Carbides during the Carbothermal Reduction of $\mathrm{WCl}_{6}$ by Hydrogen
}

\author{
Masanori Wakizaka, ${ }^{1}$ Wang-Jae Chun, ${ }^{2}$ Takane Imaoka,,${ }^{1, *}$ \\ and Kimihisa Yamamoto ${ }^{1, *}$ \\ ${ }^{1}$ Laboratory for Chemistry and Life Science Institute of Innovative Research, \\ Tokyo Institute of Technology, Yokohama 226-8503, Japan \\ ${ }^{2}$ Graduate School of Arts and Sciences, International Christian University, Tokyo 181-8585, Japan
}

Correspondence and requests for materials should be addressed to K.Y. and T.I.

E-mail: yamamoto@res.titech.ac.jp,timaoka@res.titech.ac.jp 


\section{Contents}

1. Methods

2. Figure S1. PXRD pattern of the W-powder

3. Figure S2. PXRD pattern of the sample after CHR at $1073 \mathrm{~K}$

4. Figure S3. PXRD pattern of the sample after CHR at $1173 \mathrm{~K}$

5. $\quad$ Figure S4. XPS spectra

6. $\quad$ Figure S5. W L $\mathrm{L}_{3}$ XANES spectra

7. Figure S6. $\mathrm{W} \mathrm{L}_{3}$ EXAFS oscillation

8. $\quad$ References 


\section{Methods}

XAFS analyses. ${ }^{\mathrm{S} 1, \mathrm{~S} 2}$ XAFS oscillations $\chi(k)$ were extracted using spline smoothing with a CookSayers criterion. The oscillations were normalized using an edge height with its energy dependence. The origin for the photoelectron kinetic energies $\left(E_{0}\right)$ were set at the inflection point of the absorption edge. The curve fitting for EXAFS was applied in $k$ space $\left(k=3-16 \AA^{-1}\right)$ with equations S1 and S2:

$$
\begin{aligned}
& \chi(k)=\sum_{i} \frac{N_{i} F_{i}(k) \sin \left\{2 k_{i} r_{i}+\phi_{i}\left(k_{i}\right)\right\}}{k_{i} r_{i}^{2}} \exp \left(-2 k_{i}^{2} \sigma_{i}^{2}\right) \exp \frac{-2 r_{i}}{\lambda_{i}\left(k_{i}\right)} \\
& k_{i}=\sqrt{\frac{2 m_{\mathrm{e}}}{\hbar^{2}}\left(E-E_{0}-\Delta E_{i 0}\right)}
\end{aligned}
$$

where $N_{i}, F_{i}\left(k_{i}\right), r_{i}, \phi_{i}\left(k_{i}\right), \sigma_{i}, \lambda_{\mathrm{i}}\left(k_{\mathrm{i}}\right)$, and $\Delta E_{i 0}$ represent the coordination number, the backscattering factor, the bond distance, the phase shift, the Debye-Waller factor, the photoelectron mean free path (set to $7 \AA$ ), and the difference between experimentally determined $E_{0}$ and that used for the empirical for the $i^{\text {th }}$ shell, respectively. $F_{i}\left(k_{i}\right)$ and $\phi_{i}\left(k_{i}\right)$ for the $\mathrm{W}-\mathrm{W}$ bond was obtained from the W-powder $(r$ $=2.0-2.9 \AA)$. A goodness of the curve fit $\left(R_{\mathrm{f}}\right)$ was estimated from equation S3:

$$
R_{\mathrm{f}}=\sqrt{\frac{\sum_{i} k^{n}\left\{\chi_{i}^{\mathrm{data}}(k)-\chi_{i}^{\mathrm{fit}}(k,[\alpha])\right\}^{2}}{\sum_{i}\left\{k^{n} \chi_{i}^{\mathrm{data}}(k)\right\}^{2}}}
$$

where $\chi_{i}^{\mathrm{data}}, \chi_{i}^{\mathrm{fit}}$, and $[\alpha]$ reflect the EXAFS functions from measurements, those from calculations, and the fitting parameters, respectively. 


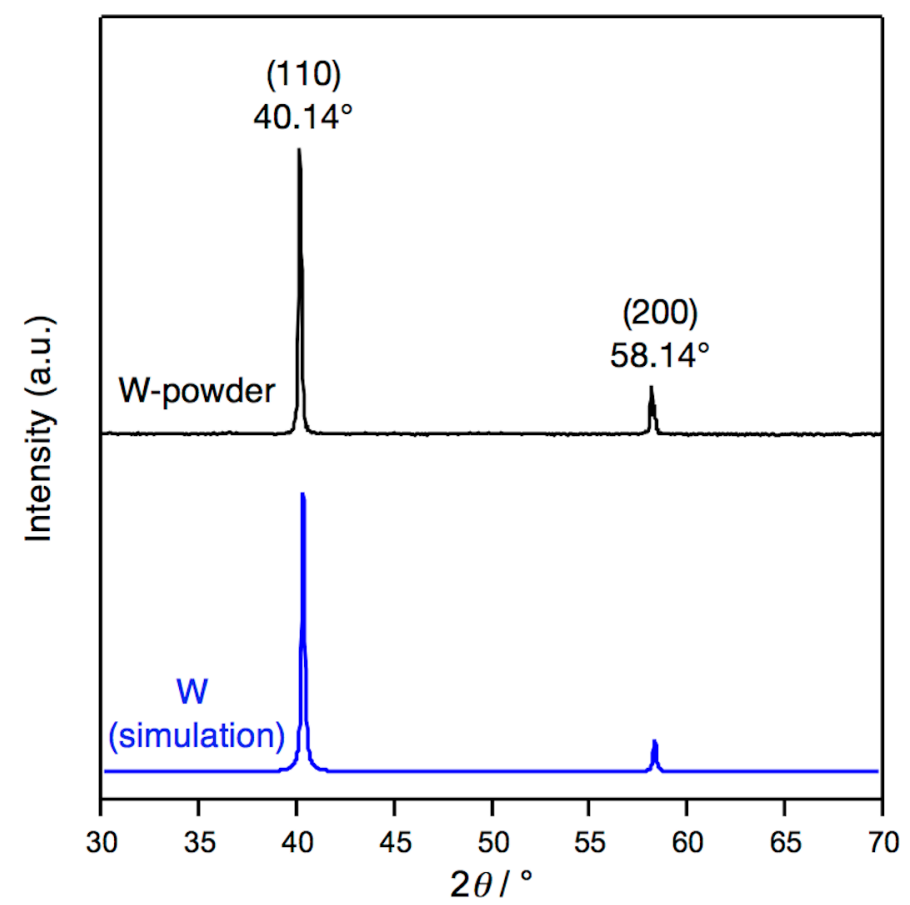

Figure S1. PXRD pattern of the W-powder (black line), together with that of the simulated pattern (blue line) for tungsten where the applied FWHM was $2 \theta=0.18^{\circ} .{ }^{\mathrm{S} 3, \mathrm{~S} 4}$

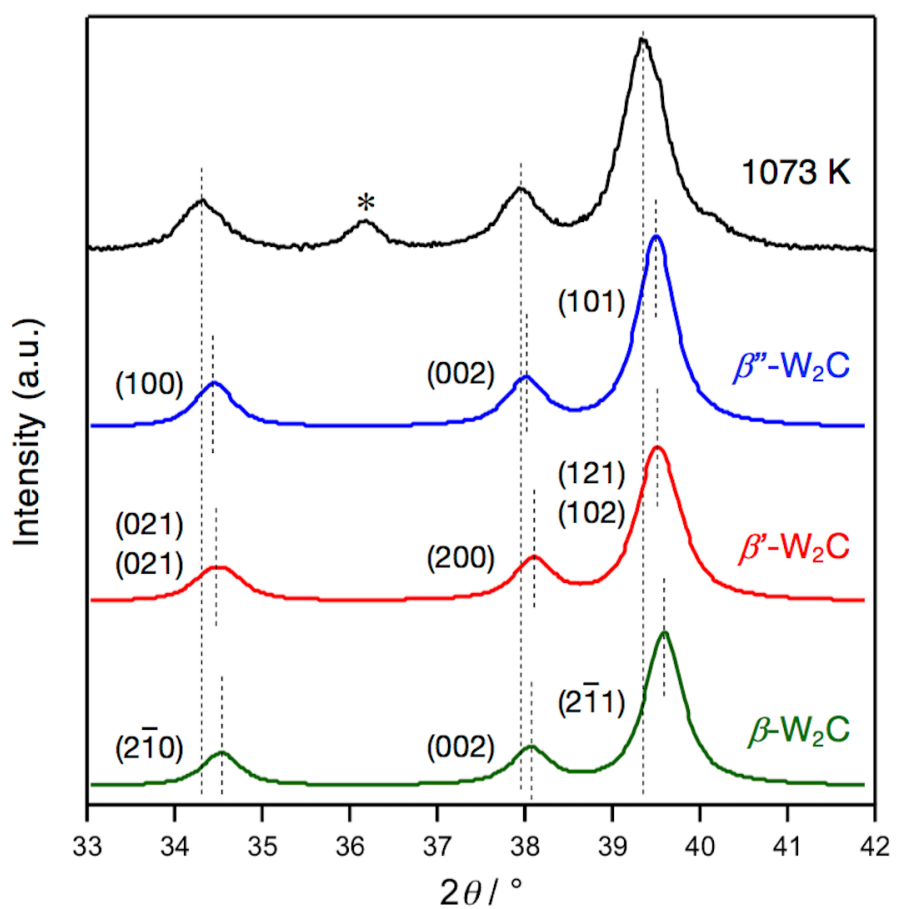

Figure S2. PXRD pattern of the sample after CHR (black line) at $1073 \mathrm{~K}$ for 30 min, together with those of the simulated patterns for $\beta^{\prime \prime}-\mathrm{W}_{2} \mathrm{C}$ (blue line), ${ }^{\mathrm{S} 3} \beta^{\prime}-\mathrm{W}_{2} \mathrm{C}$ (red line), ${ }^{\mathrm{S} 4}$ and $\beta-\mathrm{W}_{2} \mathrm{C}$ (green line ${ }^{\mathrm{S} 5}$ where the applied FWHM was $2 \theta=0.52^{\circ}$, respectively. ${ }^{\mathrm{S}}{ }^{*} *$ This peak shows the diffraction derived from a gas barrier film. 


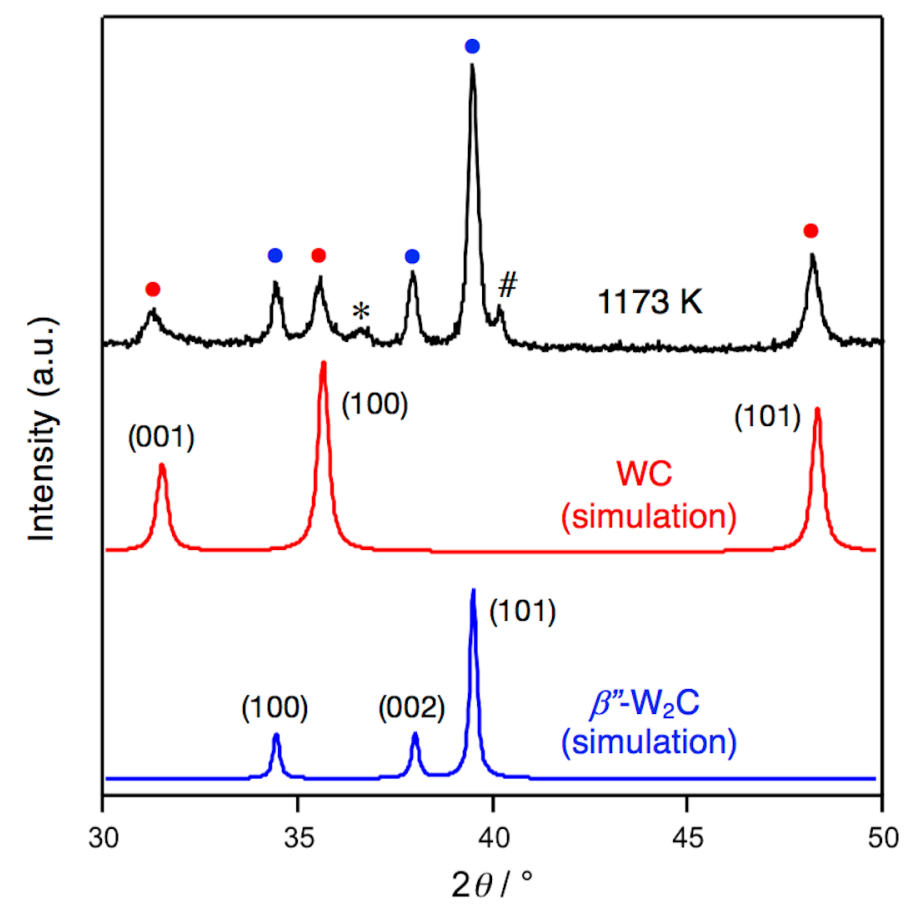

Figure S3. PXRD pattern of the sample after CHR (black line) at $1173 \mathrm{~K}$ for $3 \mathrm{~h}$, together with those of the simulated patterns for WC (red line) $)^{\mathrm{S} 6}$ and $\beta$ '”- $\mathrm{W}_{2} \mathrm{C}$ (blue line) ${ }^{\mathrm{S} 3}$ where the applied FWHM was $2 \theta=0.32$ and $0.20^{\circ}$, respectively. ${ }^{\mathrm{S}}{ }^{*}$, \# These peaks show the diffraction derived from a gas barrier film and a metallic $\mathrm{W}$, respectively. 


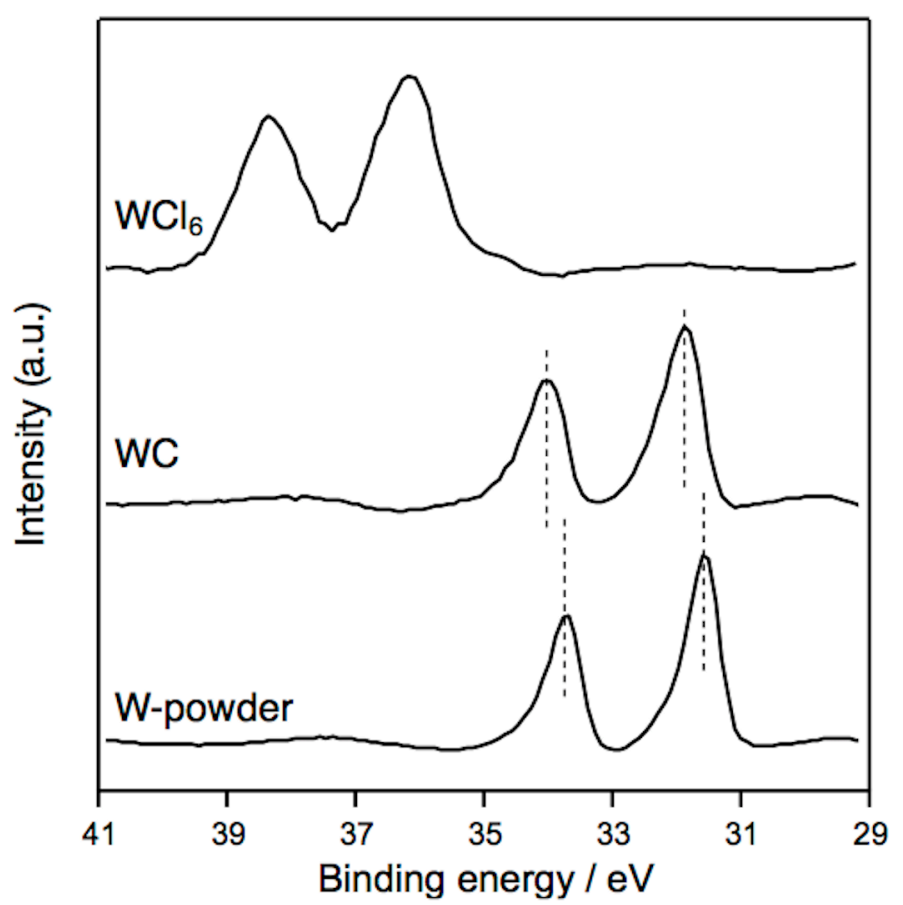

Figure S4. XPS spectra in the range of the binding energies for $W 4 f_{7 / 2}$ and $4 f_{5 / 2}$ of $W C$, together with those of $\mathrm{WCl}_{6}$ and the $\mathrm{W}$-powder on the GMC, respectively. Binding energies were calibrated by setting the $\mathrm{C} 1 \mathrm{~s}$ peak of GMC to $284.5 \mathrm{eV}$, and the experimental error was estimated to be \pm 0.1 $\mathrm{eV}$.
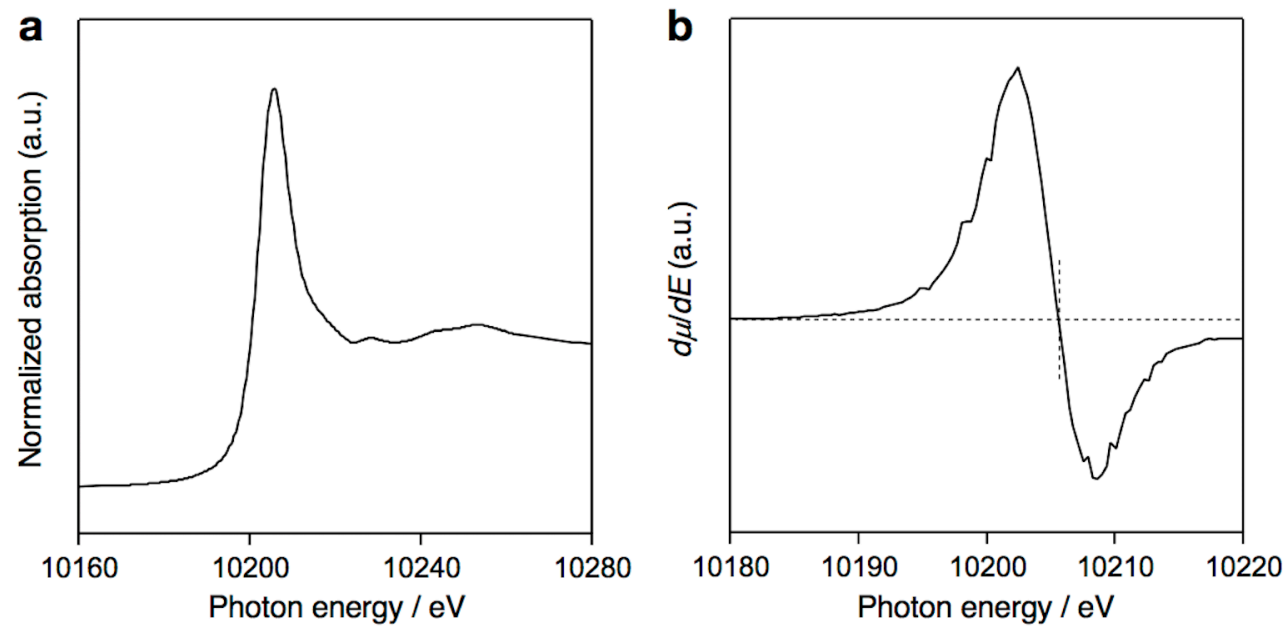

Figure S5. (a) Normalized W $\mathrm{L}_{3}$ XANES spectra and (b) first derivative spectra for WC. 


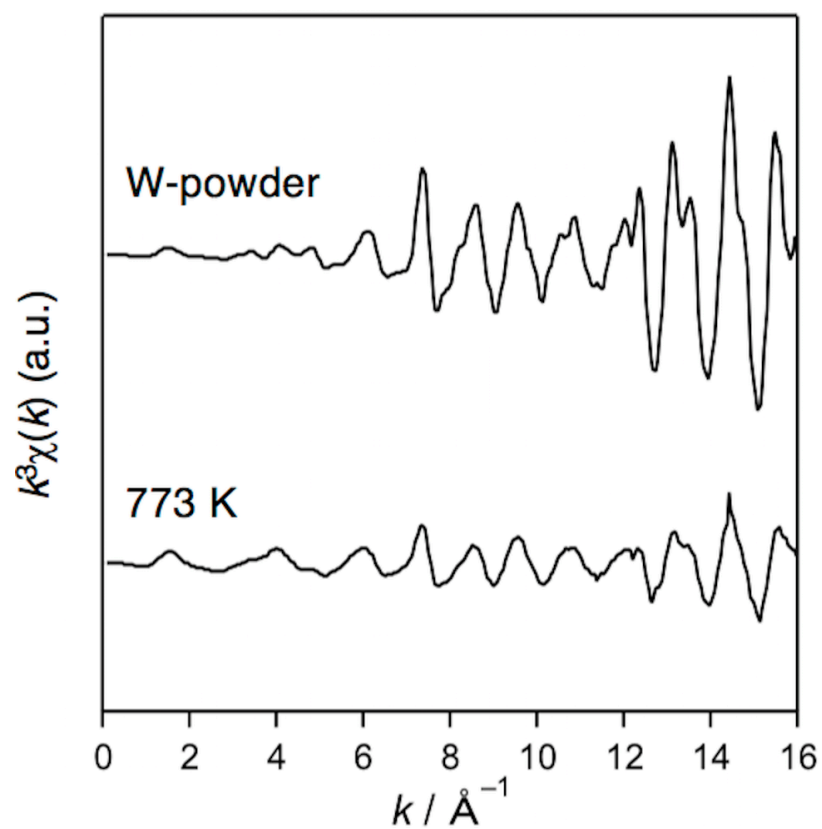

Figure S6. W $\mathrm{L}_{3}$ EXAFS oscillation of the sample obtained following CHR at $773 \mathrm{~K}$ for $30 \mathrm{~min}$, together with that of the W-powder. 


\section{References}

S1. The Japanese XAFS society, Foundations and applications of XAFS, Kodansha Ltd. 2017, Chapter 3.

S2. Taguchi, T.; Ozawa, T.; Yashiro, H. REX2000: Yet Another XAFS Analysis Package, Phy. Scr. 2005, T115, 205-206.

S3. Giorgi, A. L. Superconductivity in the W-Tc and $\mathrm{W}_{2} \mathrm{C}-\mathrm{Tc}$ Systems, Physica 1985, 135B, 420 422.

S4. Xu, Y.; Yamazaki, M.; Villars, P. Inorganic Materials Database for Exploring the Nature of Material, Jpn. J. Appl. Phys. 2011, 50, 11 RH02.

S5. Epicier, T.; Dubois, J.; Esnouf, C.; Fantozzi, G. Neutron Powder Diffraction Studies of Transition Metal Hemicarbides $\mathrm{M}_{2} \mathrm{C}_{1-x}$-II. In Situ High Temperature Study On $\mathrm{W}_{2} \mathrm{C}_{1-x}$ and $\mathrm{Mo}_{2} \mathrm{C}_{1-x}$, Acta Metall. 1988, 36, 1903-1921.

S6. Krawitz, A. D.; Reichel, D. G; Hitterman, R. Thermal Expansion of Tungsten Carbide at Low Temperature, J. Am. Cerum. Soc., 1989, 72, 515-17. 